\title{
APLIKASI PEMBELAJARAN PAI (PENDIDIKAN AGAMA ISLAM) METODE IBL (INQUIRY BASED LEARNING) BERBASIS ZONE ACTIVITY DI SEKOLAH DASAR LEBAH PUTIH SALATIGA
}

\author{
Wahyu Budi Utomo \\ IAIN Salatiga \\ E-Mail: wahyubudiutomo699@gmail.com
}

\begin{abstract}
The purpose of this study is to describe the application of Islamic religious education learning with zone based activity inquiry based learning methods implemented at SD Lebah Putih Salatiga. This research is a field research. The method used by researchers in compiling this research is a descriptive qualitative method, with a taxonomic analysis (classification) model based on focus on one domain, and only one characteristic in common. Data collected through observation, interviews, and documentation. The results of this study are applications of Islamic religious education learning with zone based activity inquiry based learning methods applied at SD Lebah Putih Salatiga, namely by making learning classified according to the abilities of each student, such as: the ability to read and write the Koran, the ability memorize short letters and the ability to understand the context of the teachings of the Koran in daily life (according to age level). Classification of abilities in understanding religion is prioritized not just in class level classification, as most schools present Islamic religious education normally. At SD Lebah Putih the learning is called Zone Activity which is a development of Morning Activity. The implementation of zone activity-based PAI learning is carried out with the following steps, such as: designing lesson plans, implementing and evaluating.
\end{abstract}

Keywords: Inquiry Based Learning, Zone Activity

Abstrak: Tujuan penelitian ini untuk mendeskripsikan Aplikasi pembelajaran pendidikan agama Islam dengan metode inquiry based learning berbasis zone activity yang diterapkan di SD Lebah Putih Salatiga. Penelitian ini adalah penelitian lapangan. Metode yang digunakan oleh peneliti dalam menyusun penelitian ini adalah metode kualitatif deskriptif, dengan model analisis taksonomi (klasifikasi) yang didasarkan fokus terhadap salah satu domain, dan hanya satu karakteristik yang sama. Data dikumpulkan melalui observasi, wawancara, dan dokumentasi. Hasil penelitian ini adalah aplikasi pembelajaran pendidikan agama Islam dengan metode inquiry based learning berbasis zone activity yang diterapkan di SD Lebah Putih Salatiga, yaitu dengan membuat pembelajarannya terklasifikasikan menurut kemampuannya masing-masing anak didik, seperti: kemampuan baca tulis al-Qur'an, kemampuan menghafal surat-surat pendek serta kemampuan memahami konteks ajaran al-Qur'an dalam kehidupan sehari-hari (sesuai tingkatan umurnya). Klasifikasi kemampuan dalam pemahaman agama lebih diprioritaskan bukan pada klasifikasi tingkat kelas saja, seperti kebanyakan sekoalah menyajikan pendidikan agama Islam biasanya. Di SD Lebah Putih pembelajaran tersebut dinamakan Zone Activity yang merupakan pengembangan dari Morning Activity. Pelaksanaan dalam pembelajaran PAI berbasis zone activity tersebut dilakukan dengan beberapa langkah berikut, seperti: perancangan RPP, pelaksanaan dan evaluasi.

Kata Kunci: Inquiry Based Learning, Zone Activity 


\section{PENDAHULUAN}

Pendidikan merupakan suatu proses dimana suatu bangsa mempersiapkan generasi mudanya untuk menjalankan kehidupan dan untuk memenuhi tujuan hidupsecara efektifdanefisien.Pendidikan juga adalah suatu proses dimana suatu bangsa atau negara membina dan mengembangkan kesadaran diri diantara individu-individu. ${ }^{1}$

Pendidikan yang dilaksanakan pada prinsipnya semua sama, yaitu memberi bimbingan agar dapat hidup mandiri sehingga dapat meneruskan dan melestarikan tradisi yang hidup di masyarakat. $^{2}$ Melalui pendidikan yang terprogram dan terkelola dengan baik dan intensif, titik optimum usaha pendidikan akan terwujud. Pendidikan dikatakan berhasil apabila mampu mengubah tingkah laku manusia ke arah yang positif. $^{3}$

Terobosan baru dalam pendidikan menjadi upaya bagi sebagian guru yang mempunyai keinginan besar dalam memajukan khazanah ilmu pengetahuan di lingkup dunia pendidikan. Munculnya beberapa metode pembelajaran adalah bukti antusias para pakar pendidikan untuk memajukan ilmu pengetahuan. Indonesia sendiri sedang marak tentang pendidikan berbasis karakter yang dipadukan dengan pendidikan agama Islam. Filsuf Yunani Aristoteles mendefinisikan karakter yang baik dalam kehidupan yaitu perilaku yang benar dalam berhubungan dengan orang lain dan dalam kaitannya dengan diri sendiri ${ }^{4}$

1 Badrus Zaman. Urgensi Pendidikan Karakter yang sesuai dengan Falsafah Bangsa Indonesia. (Jurnal Al Ghazali Vol. 2 No. 1 STAINU Purworejo: 2019) hlm. 19-20

2 Badrus Zaman. Pendidikan Akhlak pada Anak Jalanan di Surakarta. (Jurnal Inspirasi Vol. 2 No. 2 Undaris Ungaran: 2018) hlm. 130

3 Nur Apriliya Rochimah \& Badrus Zaman. 2018. Pendidikan Moral Anak Jalanan. (Yogyakarta: Trussmedia Grafika: 2018) hlm. 31

4 Thomas Licona, Educating for Character, (New York: Bantam Books, 1991) hlm 50.
Inovasi dalam dunia pembelajaran menjadi kebutuhan yang tidak bisa dielakkan, karena pembelajaran yang dilakukan di sekolah selama ini cenderung memakai metode konvensional. Metode pembelajaran konvensional adalah metode pembelajaran tradisional atau disebut juga dengan metode ceramah, karena sejak dulu metode ini telah dipergunakan sebagai alat komunikasi lisan antara guru dengan anak didik dalam proses belajar dan pembelajaran. Dalam pembelajaran apapun, metode konvensional ditandai dengan ceramah yang diiringi dengan penjelasan, serta pembagian tugas dan latihan.5

Filsafat yang mendasari pembelajaran konvensional adalah behaviorisme dalam penganutnya objectivism. Pemikiran filsafat ini memandang bahwa belajar sebagai usaha mengajarkan berbagai disiplin ilmu pengetahuan terpilih sebagai pembimbing pengetahuan terbaik. Sedangkan mengajar adalah memindahkan pengetahuan kepada orang yang belajar. Siswa sendiri diharapkan memiliki pemahaman yang sama dengan guru terhadap pengetahuan yang dipelajarinya. Tentunya dengan metode tersebut akan membuat titik jenuh yang tinggi dalam pembelajaran, untuk merubah dinamika tersebut, maka pembelajaran harus melibatkan siswa aktif dan menjadi subjek pembelajaran, bukan hanya sekedar objek yang cenderung pasif.

Pembaharuan metode pembelajaran dalam dunia pendidikan di Indonesia semakin hari mengalami perubahan yang lebih baik, demi memenuhi kebutuhan zaman yang semakin kompetitif dalam mengembangkan sumber daya manusia. Guru dituntunt untuk selalu update terhadap informasi seputar dunia

5 Eka Nella Kresma, "Perbandingan Pembelajaran Konvensional dan Pembelajaran Berbasis Masalah Terhadap Titik Jenuh Siswa Maupun Hasil Belajar Siswa dalam Pembelajaran Matematika", (Jurnal Educatio Vitae, Vol. No. 1 2014), hlm. 155. 
pendidikan, agar bisa membuat suasana pembelajaran tidak stagnan dan lebih bervariasi, selain itu guru juga dituntut untuk mengembangkan instrumen pembelajaran. Karena setiap sekolah mempunyai rumusan silabus yang berbeda-beda, tergantung dengan ciri khas masing-masing. ${ }^{6}$

Pendidikan menjadi sulit diterima di beberapa dekade terakhir ini jika seorang guru hanya mengandalkan kecerdasan kognitif dalam materi pembelajaran saja, pasalnya pendidikan hari ini jauh berbeda dengan zaman dulu. Pendidikan zaman sekarang selalu mengintegrasikan hal-hal penting dari setiah tahap pembelajarannya, dan cenderung tidak bisa mementingkan satu sisi saja, seperti mementingkan materi dari pada metode, atau sebaliknya. Salah satu pembelajaran yang mengintegrasikan beberapa elemen pendidikan adalah metode Inquiry Based Learning (IBL).

Inkuiri adalah rangkaian kegiatan pembelajaran yang menekankan pada proses berpikir secara kritis dan analitis untuk mencari dan menemukan sendiri jawaban dari suatu masalah yang dipertanyakan. ${ }^{7}$ Metode inkuiri merupakan metode yang mempersiapkan pesertadidikpadasituasiuntukmelakukan eksperimen sendiri secara luas agar melihat apa yang terjadi, ingin melakukan sesuatu, mengajukan pertanyaanpertanyaan, dan mencari jawabannya sendiri, serta menghubungkan penemuan yang satu dengan penemuan yang lain, membandingkan apa yang ditemukannya dengan yang ditemukan peserta didik lain. ${ }^{8}$ Dengan demikian kegiatan inkuiri ini dapat melatih siswa untuk belajar mandiri, sehingga akan menghasilkan

6 Siti Farikhah, Manajemen Lembaga Pendidikan, (Yogyakarta: Aswaja Pressindo, 2015) hlm 68

7 Wina Sanjaya, Strategi Pembelajaran Berorientasi Standar Proses Pendidikan, (Jakarta: Kencana, 2008) hlm194.

8 E. Mulyasa, Menjadi Guru Profesional: Menciptakan Pembelajaran Kreatif dan Menyenangkan, (Bandung: PT Remaja Rosdakarya, 2005) hlm 108 pengetahuan dan keterampilan yang bermakna bagi mereka dari pada mengingat seperangkat fakta yang diberikan guru. ${ }^{9}$

Praktik pembelajaran metode inkuiri sendiri pada dasarnya menggunakan pendekatan konstruktivistik. Di mana setiap anak didik menjadi subjek belajar, dan mereka dibebaskan untuk mencari dan menciptakan makna serta membuat pengertian baru berdasarkan pengalaman yang telah dimiliki dan dipercayai dengan ide-ide atau informasi baru yang sedang dipelajari. Dengan demikian siswa dengan segala pengalaman yang sudah dimiliki dan dipercayainya, harus memodifikasi dan membuat konstruksi baru atau menguatkan konstruksi pengalamannya dengan ilmu baru yang sedang dipelajari.

Sekolah yang menggunakan dan menekuni metode pembelajaran Inquiry Based Learning adalah SD Lebah Putih yang terletak di kota Salatiga. Walaupun sekolah tersebut masih bertaraf sekolah dasar, tetapi guru-guru yang mengajar di sekolah tersebut memanajemen metode pembelajaran tersebut agar sesuai dengan tingkat sekolah dasar. SD Lebah Putih memang terkenal dengan aktivitas yang padat dalam pembelajarannya, bahkan saking aktifnya, hari libur juga ada kegiatan yang edukatif. Dalam aktivitas yang sangat padat, bukan berarti membosankan atau membuat siswanya tertekan dengan waktu pembelajaran yang memforsir waktu bermain atau yang lainnya.

SD Lebah Putih mempunyai beberapa model pembelajaran dalam metode pembelajaran Inquiry Based Learning, salah satunya adalah model pembelajaran Zone Activity. Model pembelajaran tersebut juga dilakukan dalam mengajarkan pendidikan agama Islam (PAI). Dalam pembelajaran PAI di SD Lebah Putih cara

9 Badrus Zaman, Aplikasi Pendekatan Kontekstual pada Proses Pembelajaran Rumpun PAI, (Jurnal Profetika, Pascasarjana UMS: 2019) hlm 139 
tersendiri agar jenjang pembelajarannya jelas. Seperti yang sering terjadi dalam pendidikan agama Islam, khususnya dalam pemahaman membaca al-Quran dan kandungannya, siswa di atas kualitasnya lebih rendah dari pada yang di kelas bawahnya. Di SD Lebah Putih untuk pembelajaran agama Islam diklasifikasikan sesuai kelas dan juga ada pembelajaran sesuai kemampuan, seperti pembelajaran al-Qur'an dengan model Jari Qur'an.

\section{METODE PENELITIAN}

Penelitian yang digunakan ini menggunakan field research (penelitian lapangan) dengan pendekatan metode kualitatif. Dalam metode deskriptif kualitatif tersebut, untuk mencari pemahaman bagaimana manusia mengkonstruksi substansi dan gambaran-gambaran penting, dalam rangka intersubjektivitas. ${ }^{10}$ Metode ini dipakai sebagai sarana penelitian untuk mendeskripsikan aplikasi metode Inquiry Based Learning dalam pembelajaran pendidikan agama Islam berbasis zone activity di SD Lebah Putih.

Metode yang digunakan oleh peneliti dalam menyusun penelitian ini adalah metode kualitatif, dengan model analisis taksonomi (klasifikasi) yang didasarkan fokus terhadap salah satu domain, dan hanya satu karakteristik yang sama. ${ }^{11}$ Model ini untuk menganalisis data yang bersumber dari wawancara oleh peneliti terhadap informan secara langsung, seperti pihak yayasan, kepala sekolah, guru, dan wali murid.Selain itu juga untuk melakukan reduksi data yang memang dianggap objektif dan menunjang validitas penelitian yang dihasilkan.

10 Lexy J Moleong, Metodologi Penelitian Kualitatif, (Bandung: Remaja Rosdakarya, 2005) hlm 15.

11 Sugiyono, Metode Penelitian Pendidikan (Pendekatan Kuantitatif, Kualitatif, dan R\&D), (Bandung: Alfabeta, 2015) hlm 356
HASIL DAN PEMBAHASAN

Kebijakan Menggunakan Metode Inquiry Based Learning dalam Pembelajaran di School of Life Lebah Putih

Sekolah merupakan tempat tumbuh kembang anak yang paling ideal menurut para pakar pendidikan di zaman sekarang. Dalam sekolah disediakan beberapa instrumen yang kiranya bisa membuat lingkungan yang bersifat edukatif. Akan tetapi lain anak lain kemampuan, lain bakat dan lain minat. Banyak dari anakanak diusia sekolah yang tidak mau mengikuti pembelajaran di sekolah walapun dia termasuk anak yang mampu secara finansial, mampu secara akademis dan mampu untuk bergaul, akan tetapi dia tidak mempunyai kemauan untuk berkembang sesuai bingkai peraturan sekolah yang ada. Salah satu anak yang terbilang dari golongan diskrisi tersebut adalah Ernes, anak dari pendiri Sekolah Alam (School of Live) Lebah Putih di Salatiga.

Pendiri sekolah alam tersebut membuat lingkungan pendidikan sesuai konsep pertumbuhan anak secara alami, karena semua anak terlahir sesuai fitrahnya masing-masing. Anak terlahir dengan kecerdasan masing-masing, mereka mempunyai kecerdasan utama, dan beberapa kecerdasan yang lainnya. Melihat dari macam kecerdasan seseorang sesuai pendapatnya Howard Gardner, ada sembilan kecerdasan yang berbeda, yang mana setiap orang pasti mempunyai salah satu dari semua kecerdasan tersebut, bahkan banyak yang lebih.

Pemenuhan kebutuhan pendidikan di masyarakat tentunya berbeda-beda sesui kebutuhan dan kemampuannya. Sekolah di zaman modern yang cenderung membuat siswa dalam posisi terpojokkan oleh beberapa kurikulum yang tidak sesuai keinginan, menyebabkan banyak siswa enggan sekolah. Ernes anak pendiri sekolah alam tidak mau melanjutkan 
sekolahnya karena dirasa terlalu mengikat dan membosankan, di sekolah tidak bebas, dan kadang membatasi tumbuh kembang siswa. Anak tersebut sebenarnya sudah sekolah di SMP Nurul Islam, dan pernah juga mengikuti pembelajaran di pondok pesantren Gontor, akan tetapi dia tidak bisa bertahan sampai akhir jenjang pendidikan sekolah menengah pertama, dan akhirnya sekolahnya berhenti di tengah jalan dalam sistem sekolah formal. Menindak lanjuti anaknya yang dirasa tidak bisa mengikuti pembelajaran sekolah formal, maka Ibu Septi mencoba untuk merumuskan pendidikan untuk anaknya tersebut yang sebenarnya cukup cerdas dalam segi keilmuan. ${ }^{12}$

Perumusan sistem pembelajaran yang dibuat oleh bu Septi tentunya berbeda dengan pembelajaran yang ada di sekolah formal yang cenderung kaku dan terlalu terbebani dengan banyaknya administrasi pendidikan yang kadang guru sendiri belum bisa memahami. Rumusan yang dibuat oleh bu Septi sebisa mungkin bisa membuatanaknya merasabahagia dengan lingkungan pembelajarannya, maka ibu Septi memformulasikan pendidikan yang bersifat humanis sesuai dengan teorinya Abraham Maslow tentang kebutuhan manusia. Pendidikan yang dirasa paling humanis adalah pendidikan yang membebaskan seseorang untuk tumbuh kembang sesuai dengan keinginannya, akan tetapi juga masih memasukkan nilai-nilai kebersamaan dan penghargaan bagi alam sekitar, yang intinya semua kebebasan akan dibatasi dengan kebebasan orang lain. Jadi kebebasan yang dimaksud adalah bebas dalam mengembangkan diri, bukan bebas dalam berperlaku.

Gagasan konsep pembelajaran yang humanis memunculkan ide untuk membuat sistem pembelajaran

12 Muthoifin, Pemikiran Pendidikan Multikultural Ki Hadjar Dewantara, dalam Jurnal Intizar, Vol. 21, No. 2: 299 yang menyenangkan bagi anak didik, khususnya bagi Ernes yang pada waktu tersebut dia butuh tempat untuk belajar dan mengembangkan dirinya sesuai apa yang dia inginkan. Dengan gagasan tersebut maka dibuatlah taman belajar dan bermain untuk Ernes. Kiranya permasalahan yang menjadi kegelisahan orang tua dan dunia pendidikan di zaman modern adalah banyaknya sarana bermain yang kurang edukatif dan sering menghilangkan sisi kemanusiaan dari seorang anak yaitu permainan yang ada dalam gawai, maka sebisa mungkin konsep tempat belajar dan tumbuh kembangnya Ernes dibuat jauh dari dunia gawai dan cenderung menonjolkan sisi alami kehidupan (back to nature).

Konsep pendidikan bertema alam menjadi prioritas pada waktu tersebut agar Ernes bisa berkembang dan bersahabat dengan lingkungan, bukan berkembang akan tetapi mengabaikan hakikat-hakikat kehidupan yang ada di alam sekitarnya. Maka dibuatlah tempat pembelajaran berbasis alam di lingkungan rumahnya dengan nama saung pembelajaran lebah putih. $^{13}$

\section{Tujuan Pembelajaran PAI dengan Metode Inquiry Based Learning di School of Life Lebah Putih}

Tujuan utama dari proses pembelajaran ini, yaitu anak memahami konsep "Learning How to Learn", atau belajar bagaimana cara belajar, dan tugas guru sebagai fasilitator yang mengarahkan siswa kepada sumber belajarnya, sehingga tercipta suasana belajar yang aktif, interaktif, dimana saja, kapan saja, dan dengan siapa saja. Ujian menjadi fase "perayaan" keberhasilan proses belajar mereka (siswa dan guru) saat belajar di School of Life Lebah Putih.

13 Muthoifin, Sistem Pendidikan Nasional dan Pendidikan Islam: Studi Kritis Pemikiran Ki Hadjar Dewantara Perspektif Islam, dalam Jurnal Wahana Akademika, Vol. 2, No. 1: 69-72. 
Guru di School of Life Lebah Putih adalah fasilitator yang dapat membantu para siswa mencari sumber-sumber yang tepat untuk memenuhi rasa ingin tahu anak. Sebutan para guru di School of Life Lebah Putih adalah "Kakak", yang sangat berpengaruh terhadap proses pembelajaran. Oleh karena itu program pengembangan guru menjadi prioritas utama sekolah. Forum Pelatihan/sharing/ diskusi, dan sebagainya menjadi agenda program mingguan.

Kurikulum SD School of Life Lebah Putih meliputi kurikulum sekolah yang mengacu pada kurikulum 2013. Kurikulum ini meliputi muatan wajib, muatan lokal, pengembangan diri, pendidikan kecakapan hidup, dan pendidikan berbasis keunggulan lokal dan global.

Aplikasi Pembelajaran PAI dengan Metode Inquiry Based Learning Berbasis Zone Activity

Karakteristik metode pembelajaran inkuiri yang digunakan dalam mempermudah proses pembelajaran di sekolah:

Inkuiri menekankan kepada aktivitas peserta didik secara maksimal untuk mencari dan menemukan, inkuiri menempatkan peserta didik sebagai subjek belajar. Peserta didik tidak hanya berperan sebagai penerima pelajaran melalui penjelasan guru secara verbal, tetapi peserta didik berperan untuk menemukan sendiri inti dari materi pelajaran itu sendiri.

Seluruh aktivitas yang dilakukan peserta didik diarahkan untuk mencari dan menemukan sendiri dari sesuatu yang dipertanyakan. Pembelajaran inkuirimenempatkangurubukan sebagai sumber belajar, akan tetapi sebagai fasilitator dan motivator belajar peserta didik. Aktivitas pembelajaran biasanya dilakukan melalui proses tanya jawab antara guru dan peserta didik, sehingga kemampuan guru dalam menggunakan teknik bertanya merupakan syarat utama dalam melakukan inkuiri.

\begin{tabular}{lr}
\multicolumn{1}{c}{ Tujuan dari } & penggunaan \\
pembelajaran & inkuiri $\begin{array}{r}\text { adalah } \\
\text { mengembangkan }\end{array}$
\end{tabular} intelektual sebagai bagian dari proses mental, akibatnya dalam pembelajaran inkuiri peserta didik tidak hanya dituntut agar menguasai pelajaran, akan tetapi bagaimana peserta didik dapat menggunakan potensi yang dimilikinya. ${ }^{14}$

\section{Tahapan Metode Pembelajan Inquiry Based Learning Terbimbing}

Inisiasi: Guru memulai proses penyelidikkan dengan menjelaskan materi yang akan dipelajari dengan cara membangun pemikiran peserta didik. Guru memotivasi peserta didik sebelum memulai topik pelajaran dengan harapan peserta didik tidak merasa ertekan dalam mempelajari materi.

Seleksi: Peserta didik memilih topik secara umum dan menyiapkan pertanyaan tentang materi yang akan dipelajari. Topik-topik tersebut dapat dipilih berdasarkan kepentingan pribadi, persyaratan tugas informasi yang tersedia dan waktu yang diberikan.

Eksplorasi: Peserta didik mencari informasi materi pelajaran dan mengidentifikasi cara yang mungkin dapat dilakukan dari berbagai sumber. Bagi kebanyakkan peserta didik, ini adalah tahap yang paling sulit dari proses penelitian.

Formulasi: Peserta didik diberikan waktu untuk membentuk informasi yang ereka temukan dalam berbagai konsep. Peserta didik perlu mengidentifikasi dan mengumpulkan informasi yang di dapat menjadi satu-kesatuan yang terfokus.

Koleksi: Peserta didik harus dapat

14 Wina Sanjaya, Strategi Pembelajaran Berorientasi Standar Proses Pendidikan, Cet. 5, (Jakarta :Kencana Prenada Media Group, 2008) hlm 196-197. 
memperluas materi dalam pengetahuan atau pemahaman yang baru. Kepercayaan diri dapat meningkatkan minat dan mengembangkan keahlian peserta didik.

Presentasi: Tahap ini puncak dari proses penyelidikkan, peserta didik berbagi informasi yang didapat dengan orang lain. Kegiatan ini membentuk dasar penyelidikkan untuk menilai informasi yang salah.
Penilaian: Tahap ini peserta didik dan guru menilai apa yang telah dipelajari. Tahap ini adalah merefleksikan proses penyelidikkan untuk mengevaluasi proses yang telah dilakukan. Tahap ini merupakan kesempatan untuk merefleksikan proses secara keseluruhan. ${ }^{15}$

15 Carol C. Kuhlthau, Leslie K. Maniotes, dan Ann K. Caspari, Guided Inquiry Learning in 21st Century, Cet. 1, (London: Libraries Unlimited, 2007) hlm 4.

Tabel 1. Tahapan dalam Pembelajaran IBL

\begin{tabular}{|c|c|}
\hline Tahapan & Kegiatan Pembelajaran \\
\hline $\begin{array}{l}\text { Pengajuan pertanyaan } \\
\text { atau permasalahan }\end{array}$ & $\begin{array}{l}\text { Kegiatan dimulai ketika guru memberikan pertanyaan atau permasalahan, } \\
\text { dan peserta didik diminta untuk merumuskan hipotesis. }\end{array}$ \\
\hline Merumuskan hipotesis & $\begin{array}{l}\text { Peserta didik mengajukan jawaban sementara atas pertanyaan atau solusi } \\
\text { permasalahan yang dapat diuji dengan data. Hal ini untuk memudahkan } \\
\text { guru memberikan kebebasan kepada peserta didik untuk mengemukakan } \\
\text { hipotesis kemudian membimbing peserta didik untuk memilih salah satu } \\
\text { hipotesis yang relevan dengan permasalahan. }\end{array}$ \\
\hline Mengumpulkan data & $\begin{array}{l}\text { Tahap pengumpulan data ini dapat dilaksanakan dengan melakukan kegiatan } \\
\text { eksperimen, demonstrasi, menyimak simulasi, dsb. Data yang dihasilkan } \\
\text { dapat berupa Tabel, matrik, atau grafik }\end{array}$ \\
\hline Analisis data & $\begin{array}{l}\text { Data yang telah diperoleh kemudian diolah dan dianalisis untuk menguji } \\
\text { hipotesis yang telah dirumuskan. Bila ternyata hipotesis yang telah } \\
\text { dirumuskan salah atau ditolak, peserta didik dapat menjelaskan sesuai } \\
\text { dengan proses inkuiri yang telah dilakukan. }\end{array}$ \\
\hline Membuat kesimpulan & $\begin{array}{l}\text { Peserta didik membuat kesimpulan sementara berdasarkan data yang } \\
\text { diperoleh dan hasil analisis data yang telah dilakukan. }\end{array}$ \\
\hline
\end{tabular}

Kegiatan pembelajaran Agama Islam selama ini terkesan monoton dengan pemahaman yang sudah dimiliki oleh siswa. Pembelajaran dengan metode inquiry based learning mengupayakan agar proses pembelajaran yang ada dalam lingkup dunia pendidikan tidak stagnan dan cenderung bisa berkembang dengan melibatkan siswa ikut aktif dalam berkontribusi menyumbang peranan dalam jalannya pembelajaran.

Metode pembelajaran inquiry based learning memang banyak yang meragukan untuk diterapkan di tingkat sekolah dasar, karena metode tersebut lebih akrab dengan pendidikan di perguruan tinggi. Akan tetapi bukan berarti tidak bisa diterapkan ketika sudah dilakukan inovasi, seperti yang dilakukan di SD Lebah Putih Salatiga. Di sekolah tersebut pembelajaran pendidikan agama Islam diajarkan dengan menggunkana metode inquiry based learning agar ada perubahan dalam konsep pembelajaran yang sudah mulai tidak relevan dengan zaman. Seperti yang sudah berjalan dengan kurun waktu yang sangat lama, pendidikan agama Islam lebih banyak diajarkan dengan ceramah, praktik pengetahuan agama dan mulai ada sedikit pengembangan dengan diskusi tentang mata pelajaran agama Islam akan tetapi tidak sesuai porsi anak sekolah dasar.

Konsep pembelajaran pendidikan 
agama Islam dengan metode inquiry based learning yang diterapkan di SD Lebah Putih Salatiga dengan membuat pembelajarannya diklasifikasikan menurut kemampuannya masingmasing, bukan dengan klasifikasi tingkat kelas saja, seperti kebanyakan sekoalah menyajikan pendidikan agama Islam biasanya. Di SD Lebah Putih pembelajaran tersebut dinamakan Zone Activity yang merupakan pengembangan dari Morning Activity.

Pembelajaran pendidikan agama Islam dengan model zone activity mengklasifikasikan pembelajaran dengan tiga kelompok pembelajaran, yaitu: Jari Qur'an, Iman dan Taqwa dan Sharing sasion. Aktivitas pembelajaran tersebut, semuanya melibatkan keaktivan siswa dalam prosesnya. Kontribusi siswa dalam pembelajaran tersebut tentunya sangat berbeda dengan bangku perguruan tinggi, karena tingkat kemampuan dalam memahami dan mengeksplorasi pelajaran yang diberikan berbeda.

Dalam pelaksanaan ketiga zona pembelajaran pendidikan agama Islam tersebut di SD Lebah Putih juga diklasifikasikan sesuai kemampuan dan kelasnya, seperti zona Jari Qur'an dan Iman dan Taqwa diperuntukkan untuk siswa kelas 1-3 yang masih dalam proses belajar membaca al-Qur'an. Akan tetapi siswa kelas 1-3 ketika sudah bisa dan lancar dalam membaca al-Qur'an, selain itu juga bisa menghafal beberapa surat pendek, maka diperbolehkan untuk mengikuti pembelajaran pendidikan agama Islam yang ada di tingkat selanjutnya yang bernama sharing sasion. Dalam kesehariannya siswa boleh memilih untuk belajar tentang agama Islam di kelompok jari Qur'an atau di kelompok Iman dan Taqwa, sesuai keinginan mereka, agar mereka tidak terlalu jenuh dan cenderung lebih ceria dengan keadaan kelas yang berbeda-beda.
Kelompok pembelajaran agama Islam dijenjang selanjutnya yaitu Sharing Sasion. Tigkatan ini diperuntukkan untuk siswa kelas4-6yang mempunyai kecenderungan mulai bisa berpikir abstrak seperti dalam perkembangan kognitifnya Peaget. Siswa kelas 4-6 dengan kemampuan berpikir yang sudah berkembang beda dengan kelas 1-3 diarahkan untuk mengkonstruk pemahaman agama Islam melalui kejadian dalam kehidupan sehari-hari. Akan tetapi jika ada siswa kelas 4-6 belum bisa membaca al-Qur'an dengan lancar dan belum mempunyai bekal hafalan beberapa surat pendek, maka siswa tersebut kesehariannya dalam pembelajaran agama Islam masuk di kelompok zona jari Quran atau zona Iman dan Taqwa, sesuai keinginan siswa tersebut.

Sharing Sasion yang kebanyakan diisi oleh siswa kelas 4-6 mempermudah guru untuk mengekplorasi dinamika kehidupan sehari-hari yang ada dalam lingkungan anak didiknya, khususnya tentang probelematikan dan pemahaman keagamaan siswa. Guru dalam Sharing Sasion selalu mempertanyakan tentang beberapa peristiwa yang terjadi di sekeliling siswa,hal tersebut dilakukan dalam rangka memberikan stimulus terhadap pemahaman dan respon siswa terhadap kejadian yang ada di sekelilingnya. Dengan cara tersebut guru akan mulai membaca dan memahami perkembangan siswanya, sehingga seorang guru yang mengisi dalam zona Sharing Sasion akan mencoba mengkomparasi pembhaman dan siskap siswa dengan materi pembelajaran agama Islam yang sudah disiapkan.

Guru dalam melibatkan siswa untuk pembelajaran agama Islam di zona Sharing Sasion, bertujuan agar bisa membuat siswa aktif dan resposif dengan permasalahan yang ada. Pembelajaran yang selalu bertujuan dalam mengembangkan aspek 
kognitif, afektif dan psikomotorik siswa, tentunya lebih mudah dicapai ketika siswa aktif. Seperti itulah mengapa penerapan metode pembelajaran agama Islam di SD Lebah Putih menggunakan metode pembeljaran inquiry based learning yang sudah dikontekstualkan dengan kemampuan dan kebutuhan siswa sekolah dasar.

\section{PENUTUP}

Aplikasi pembelajaran pendidikan agama Islam dengan metode inquiry based learning berbasis zone activity yang diterapkan di SD Lebah Putih Salatiga, yaitu dengan membuat pembelajarannya terklasifikasikan menurut kemampuannya masing-masing anak didik, seperti: kemampuan baca tulis al-Qur'an, kemampuan menghafal surat-surat pendek serta kemampuan memahamikonteksajaranal-Qur'andalam kehidupan sehari-hari (sesuai tingkatan umurnya). Klasifikasi kemampuan dalam pemahaman agama lebih diprioritaskan bukan pada klasifikasi tingkat kelas saja, seperti kebanyakan sekoalah menyajikan pendidikan agama Islam biasanya. Di SD Lebah Putih pembelajaran tersebut dinamakan Zone Activity yang merupakan pengembangan dari Morning Activity. Pelaksanaan dalam pembelajaran PAI berbasis zone activity tersebut dilakukan dengan beberapa langkah berikut, seperti: perancangan RPP, pelaksanaan dan evaluasi.

Aktivitas pembelajaran siswa dalam mata pelajaran PAI antara lain terwujud dalam kegiatan-kegiatan aktif, seperti mengidentifikasi dan menanya, kerja sama antar kelompok belajar, belajar di alam terbuka, belajar mandiri sesuai program capaian pribadi, serta pengembangan kemampuan dalam mengkonstruksi pengalaman belajarnya

\section{DAFTAR PUSTAKA}

Farikhah, Siti, Manajemen Lembaga Pendidikan, Yogyakarta: Aswaja Pressindo, 2015.

Kresma, Eka Nella, "Perbandingan Pembelajaran Konvensional Dan Pembelajaran Berbasis Masalah Terhadap Titik Jenuh Siswa Maupun Hasil Belajar Siswa Dalam Pembelajaran Matematika", Educatio Vitae, Vol. No. 1 (2014), 152-164.

Kuhlthau C. Carol Leslie K. Maniotes, dan Ann K. Caspari, 2007. Guided Inquiry Learning in 21st Century, Cet. 1. London: Libraries Unlimited

Licona, Thomas, Educating for Character, New York: Bantam Books, 1991.

Moleong, Lexy J., Metode Penelitian Kualitaif, Bandung: Remaja Rosdakarya, 2005.

Mulyasa, E., MenjadiGuru Profesional:Menciptakan Pembelajaran KreatifdanMenyenangkan, Bandung: PT Remaja Rosdakarya, 2005.

Muthoifin. 2015. Pemikiran Pendidikan Multikultural Ki Hadjar Dewantara, dalam Jurnal Intizar, Vol. 21, No. 2: 299.

Muthoifin. 2015. Sistem Pendidikan Nasional dan Pendidikan Islam: Studi Kritis Pemikiran Ki Hadjar Dewantara Perspektif Islam, dalam Jurnal Wahana Akademika, Vol. 2, No. 1: 69-72.

Rochimah, Nur Apriliya \& Badrus Zaman. 2018. Pendidikan Moral Anak Jalanan. Yogyakarta: Trussmedia Grafika.

Sanjaya, Wina, 2008. Strategi Pembelajaran Berorientasi Standar Proses Pendidikan, Jakarta: Kencana, 2008. 
PROFETIKA, Jurnal Studi Islam, Vol.21, No. 1, Special Issue 2020: 99-108

Zaman, Badrus. 2018. Pendidikan Akhlak pada Anak Jalanan di Surakarta. Jurnal Inspirasi Vol. 2 No. 2 Undaris Ungaran.

Zaman, Badrus. 2019. Urgensi Pendidikan Karakter yang sesuai dengan Falsafah Bangsa Indonesia. Jurnal Al Ghazali Vol. 2 No. 1 STAINU Purworejo.

Zaman, Badrus, 2019. Aplikasi Pendekatan Kontekstual pada Proses Pembelajaran Rumpun PAI, Jurnal Profetika Vol. 20, No. 2 Pascasarjana UMS. 